\title{
Prevention of osteoporosis by angiotensin-converting enzyme inhibitor in spontaneous hypertensive rats
}

\author{
Hideo Shimizu ${ }^{1,2}$, Hironori Nakagami ${ }^{3}$, Mariana Kiomy Osako ${ }^{1}$, Futoshi Nakagami ${ }^{1,2}$, Yasuo Kunugiza ${ }^{4}$, \\ Tetsuya Tomita $^{4}$, Hideki Yoshikawa ${ }^{4}$, Hiromi Rakugi ${ }^{2}$, Toshio Ogihara ${ }^{5}$ and Ryuichi Morishita ${ }^{1}$
}

A recent analysis of clinical studies suggests that angiotensin-converting enzyme (ACE) inhibitors might reduce bone fractures. In this study, we examined whether an ACE inhibitor might attenuate osteoporosis in a hypertensive rat model. In spontaneous hypertensive rats (SHRs), estrogen deficiency induced by ovariectomy (OVX) resulted in a significant increase in osteoclast activation as assessed by the tartrate-resistant acid phosphatase (TRAP) activity in the tibia, accompanied by a significant decrease in bone density evaluated by dual-energy X-ray absorptiometry and an increase in urinary deoxypyridinoline. Treatment with an ACE inhibitor, imidapril, attenuated OVX-induced decrease in bone density and increase in TRAP activity and urinary deoxypyridinoline. As ACE inhibitors possess the effects of blockade of the renin-angiotensin system (RAS) and activation of the bradykinin-nitric oxide pathway, we examined the contribution of both pathways in an OVX-induced osteoporosis model. Administration of nitro-L-arginine methylester (L-NAME) did not alter TRAP activity, urinary deoxypyridinoline or bone density, whereas the administration of a subpressor dose of angiotensin II accelerated the increase in TRAP activity in the tibia, accompanied by a significant decrease in bone density and an increase in urinary deoxypyridinoline. Thus, ACE inhibitors prevented osteoporosis, probably because of the inhibition of RAS, but not of nitric oxide. Overall, ACE inhibitors attenuated osteoporosis in a hypertensive rat model through the blockade of RAS.

Hypertension Research (2009) 32, 786-790; doi:10.1038/hr.2009.99; published online 10 July 2009

Keywords: bone; renin-angiotensin system; osteoporosis

\section{INTRODUCTION}

Hypertension and osteoporosis are two common diseases in the elderly population, and $50 \%$ of the hypertensive population comprises postmenopausal women at high risk of osteoporosis. Compared with healthy controls, reduced bone mineral density (BMD) has been found in patients with hypertension or ischemic heart disease. ${ }^{1-4}$ Clinical studies have shown significant abnormalities in calcium metabolism in hypertension, ${ }^{5-7}$ and a decreased circulating level of calcium results in an increased parathyroid hormone, which is implicated in the occurrence and/or development of hypertension. ${ }^{8}$ Animal and epidemiological evidence suggests that high blood pressure is associated with abnormalities of calcium metabolism, leading to an increase in calcium loss, to a secondary activation of the parathyroid gland and to an increased movement of calcium from bone, thereby increasing the risk of osteoporosis. ${ }^{7,9}$ Indeed, clinical studies have shown considerable evidence that antihypertensive drugs such as thiazides decreased the risk of hip fracture by reducing renal calcium excretion. ${ }^{10,11}$ Interestingly, angiotensin-converting enzyme (ACE) inhibitors are also reported to reduce the risk of fractures. ${ }^{12-14}$
Recently, we reported that angiotensin (Ang) II activated osteoclasts, leading to osteoporosis. ${ }^{15}$ As vasculature has an important role in bone remodeling, the effect of ACE inhibitors on bone metabolism may not only be a blockade of the renin-angiotensin system (RAS) but may also be related to the regulation of blood flow through the regulation of the bradykinin-nitric oxide pathway. Therefore, in this study, we examined the effect of an ACE inhibitor, imidapril, in an osteoporosis model in hypertensive rats, especially focusing on osteoclast activation.

\section{METHODS}

Rat ovariectomy osteoporosis model

All experiments were approved by the Ethical Committee for animal experiments at the Osaka University Graduate School of Medicine. Female adult Wistar rats (10-weeks old) were purchased from SLC Japan (Shizuoka, Japan). After the rats were anesthetized with intraperitoneal ketamine $\left(80 \mathrm{mg} \mathrm{kg}^{-1}\right)$ and xylazine $\left(10 \mathrm{mg} \mathrm{kg}^{-1}\right)$, bilateral ovariectomy (OVX) or sham operation was performed, and nitro-L-arginine methylester (L-NAME, Sigma, St Louis, MO, USA) was administered along with drinking water $\left(1 \mathrm{mg} \mathrm{ml}^{-1}\right) \cdot{ }^{16}$ Female adult

${ }^{1}$ Department of Clinical Gene Therapy, Osaka University Graduate School of Medicine, Suita, Osaka, Japan; ${ }^{2}$ Department of Geriatric Medicine, Osaka University Graduate School of Medicine, Suita, Osaka, Japan; ${ }^{3}$ Division of Gene Therapy Science, Osaka University Graduate School of Medicine, Suita, Osaka, Japan; ${ }^{4}$ Department of Orthopaedic Surgery, Osaka University Graduate School of Medicine, Suita, Osaka, Japan and ${ }^{5}$ Osaka General Medical Center, Sumiyoshi-ku, Osaka, Japan

Correspondence: Professor R Morishita, Department of Clinical Gene Therapy, Osaka University Graduate School of Medicine, 2-2 Yamadaoka, Suita, Osaka 565-0871, Japan. E-mail: morishit@cgt.med.osaka-u.ac.jp

Received 27 December 2008; revised 16 May 2009; accepted 2 June 2009; published online 10 July 2009 
spontaneous hypertensive rats (SHRs) (10-weeks old) were also purchased from SLC Japan), and bilateral OVX or sham operation was performed. In some groups of rats, imidapril ( 1 or $3 \mathrm{mg} \mathrm{kg}^{-1}$ per day) was administered along with drinking water. The body weight of these rats was recorded for 4 weeks. At 4 weeks after operation, systolic blood pressure was measured using the tail-cuff method (BP-98A, Softron, Koenji, Tokyo, Japan), and urinary deoxypiridinorine was measured by EIA (Metra Biosystems, Mountain View, CA, USA). They were strongly anesthetized and killed to collect femurs, tibias and blood for biochemical analysis.

\section{Activity of ALP and tartrate-resistant acid phosphatase}

Alkaline phosphatase (ALP) activity was measured for the evaluation of osteoblast activity, and tartrate-resistant acid phosphatase (TRAP) was measured for the evaluation of osteoclast activity, as previously described. ${ }^{15}$ Proximal tibia and distal femur were excised and homogenized in $10 \mathrm{mmoll}^{-1}$ triethanolamine buffer ( $\mathrm{pH}$ 7.5) for TRAP, and in diethanolamine buffer ( $\mathrm{pH}$ 9.8) for ALP activity. Supernatants were subjected to a measurement of TRAP activity as previously described. ${ }^{17}$ For ALP activity, supernatants were incubated with p-nitrophenylphosphate as a substrate for $30 \mathrm{~min}$ at $25^{\circ} \mathrm{C}$, and absorbance was measured at $405 \mathrm{~nm}$ and converted into unit (U: $1 \mathrm{u}$ indicates the release of $1 \mu \mathrm{mol}$ p-nitrophenol per minute). The urinary deoxypyridinoline level was measured by EIA on day 28 of the experiment.

Serum calcium, phosphate, ALP and urinary calcium were measured in Falco Biosystems (Osaka, Japan) on day 28 of the experiment. Serum osteocalcin was measured by EIA (Takara MK121 Rat Gla-OC Competitive EIA Kit, Otsu, Shiga, Japan).

\section{Dual-energy X-ray absorptiometry}

Bone density measurements were determined by dual-energy X-ray absorptiometry (DEXA) bone densitometry (GE-Lunar DPX-IQ, Madison, WI, USA). High- and low-beam energies for all scans were 80 and $35 \mathrm{kV}$, respectively, at $0.5 \mathrm{~mA}$, as previously described. ${ }^{18} \mathrm{BMD}$ was obtained in $\mathrm{g} \mathrm{cm}^{-2}$.

\section{Statistical analysis}

All values are expressed as mean \pm s.e.m. Analysis of variance with subsequent Bonferroni's/Dunnet's test was used to determine the significance of differences in multiple comparisons. Values of $P<0.05$ were considered to be statistically significant.

\section{RESULTS}

Imidapril ameliorated OVX-induced osteoporosis

To clarify the effect of ACE inhibition on bone metabolism, we used an OVX model of estrogen deficiency in a hypertension model, SHR. ${ }^{15}$ At 28 days after bilateral OVX, both ALP and TRAP activities were increased in the tibia of ovariectomized SHR as compared with those in sham-operated SHR (Figures 1a and b). As TRAP activity was significantly increased, the ratio of ALP to TRAP was markedly a

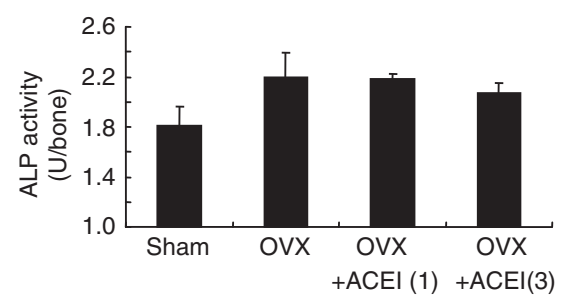

b

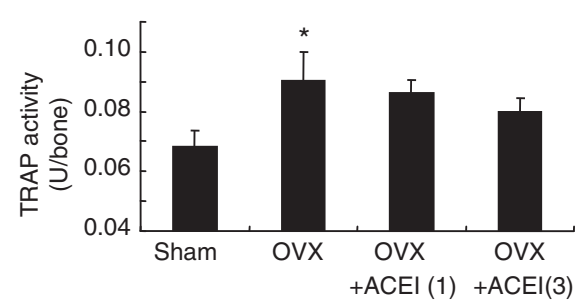

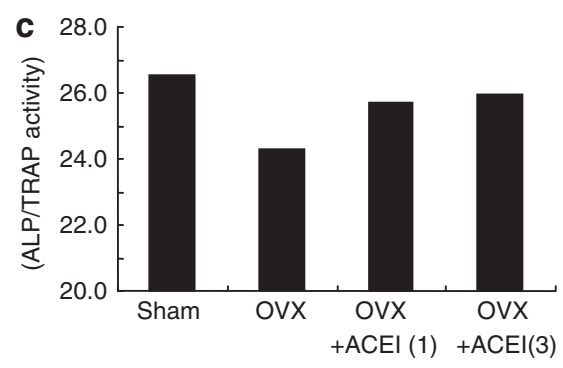
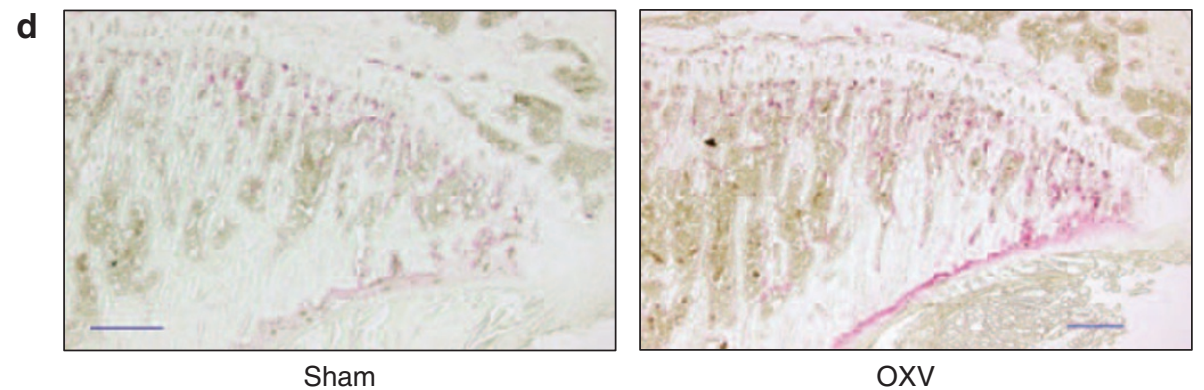

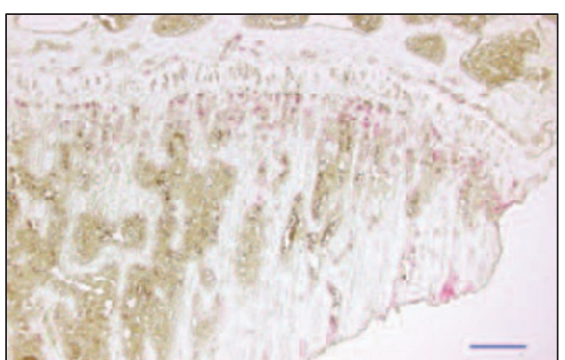

OVX + ACEI (1)

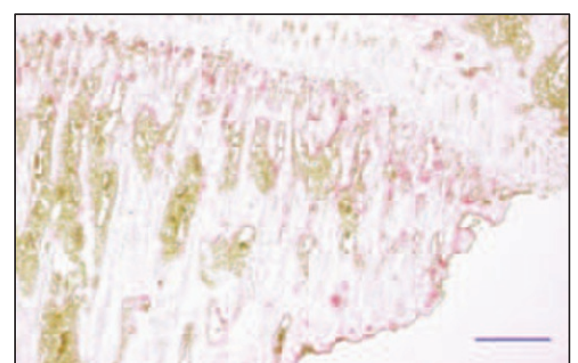

OVX + ACEI (3)

Figure 1 Effects of angiotensin-converting enzyme (ACE) inhibitor, imidapril, on alkaline phosphatase (ALP) and tartrate-resistant acid phosphatase (TRAP) activity in ovariectomized spontaneous hypertensive rats (SHRs). (a) ALP activity, (b) TRAP activity, (c) ratio of ALP to TRAP activity, (d) TRAP staining after 28 days of each treatment. Sham=sham operation; OVX=bilateral ovariectomy; OVX+ACEI(1)=bilateral ovariectomy and treatment with an $A C E$ inhibitor, imidapril ( $1 \mathrm{mg} \mathrm{kg}^{-1}$ per day); $\mathrm{OVX}+\mathrm{ACEI}(3)=$ bilateral ovariectomy and treatment with an ACE inhibitor, imidapril $\left(3 \mathrm{mg} \mathrm{kg}^{-1}\right.$ per day). ${ }^{*} P<0.05 \mathrm{vs}$. sham, $\dagger P<0.05$ vs. OVX, $N=6-10$ per group. Bar indicates $0.3 \mathrm{~mm}$. 
Table 1 Blood pressure and heart rate of each group

\begin{tabular}{llcll}
\hline & SBP & DBP & \multicolumn{1}{c}{$H R$} & \multicolumn{1}{c}{$B W$} \\
\hline Sham & $148 \pm 2.4$ & $105 \pm 3.4$ & $350 \pm 11.4$ & $228 \pm 4.5$ \\
OVX & $146 \pm 5.1$ & $101 \pm 3.4$ & $358 \pm 14.4$ & $262 \pm 3.2^{\#}$ \\
+ACEI(1) & $121 \pm 1.5^{*}$ & $90 \pm 2.7^{*}$ & $355 \pm 7.2$ & $256 \pm 5.0$ \\
+ACEI(3) & $119 \pm 5.5^{*}$ & $84 \pm 2.3^{*}$ & $323 \pm 4.4$ & $241 \pm 4.8$
\end{tabular}

Abbreviations: ACEI(1 or 3), angiotensin converting enzyme inhibitor, imidapril, ( 1 or $3 \mathrm{mg} \mathrm{kg}^{-1}$ per day); BW, body weight (g); DBP, diastolic blood pressure $(\mathrm{mm} \mathrm{Hg})$; $\mathrm{HR}$, heart rate (beats per minute, b.p.m.); OVX, overiectomy; SBP, systolic blood pressure $(\mathrm{mm} \mathrm{Hg})$.

${ }^{*} P<0.05$ vs. OVX; $\# P<0.05$ vs. sham.
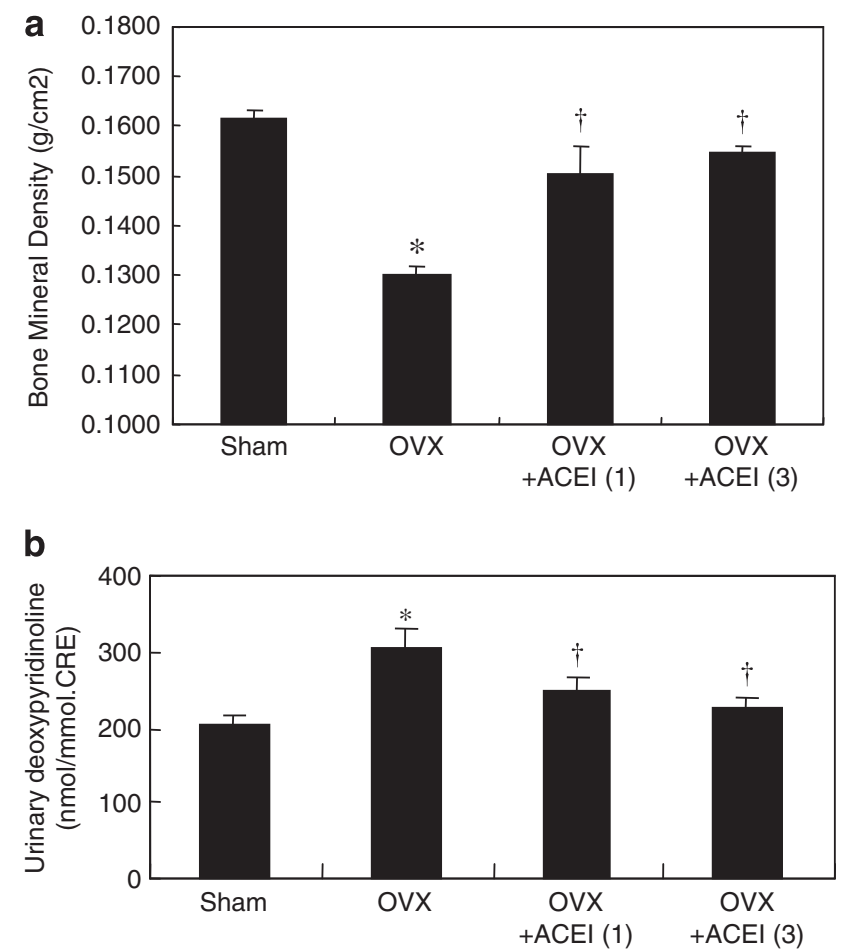

Figure 2 Effects of angiotensin-converting enzyme (ACE) inhibitor, imidapril, on urinary deoxypyridinoline and bone density in ovariectomized spontaneous hypertensive rats (SHRs). (a) Bone mineral density by dualenergy X-ray absorptiometry (DEXA) and (b) urinary deoxypyridinoline after 28 days of each treatment. Sham, sham operation; OVX, bilateral ovariectomy; OVX+ACEI(1), bilateral ovariectomy and treatment with an ACE inhibitor, imidapril ( $1 \mathrm{mg} \mathrm{kg}^{-1}$ per day); OVX+ACEI(3)=bilateral ovariectomy and treatment with an ACE inhibitor, imidapril $\left(3 \mathrm{mg} \mathrm{kg}^{-1}\right.$ per day). ${ }^{*} P<0.05$ vs. sham, ${ }^{\dagger} P<0.05$ vs. OVX, $N, 6-10$ per group.

decreased in the tibia of ovariectomized SHR as compared with that in sham-operated rats (Figure 1c). In this model, the administration of imidapril ( 1 or $3 \mathrm{mg} \mathrm{kg}^{-1}$ per day in drinking water) significantly decreased blood pressure, but not body weight, as shown in Table 1 . The OVX-induced decrease in the ratio of ALP to TRAP activity was significantly ameliorated by imidapril (Figure 1c). Indeed, the TRAPpositive stained area was increased in the tibia of ovariectomized SHR, whereas treatment with imidapril significantly decreased the TRAPpositive stained area (Figure 1d). Importantly, these results were accompanied by a significant decrease in BMD in ovariectomized SHR, as assessed by DEXA, which was attenuated by the administration of imidapril (Figure 2a). Consistently, the increase in urinary deoxypyridinoline was significantly attenuated by imidapril (Figure 2b). We further analyzed the serum bone-related markers in
Table 2 Serum bone-related marker of each group

\begin{tabular}{lcccr}
\hline & Ca & $P$ & ALP3 & Osteocalcin \\
\hline Sham & $9.9 \pm 0.3$ & $6.3 \pm 0.3$ & $166 \pm 6.0$ & $951 \pm 13.6$ \\
OVX & $9.7 \pm 0.3$ & $6.4 \pm 0.3$ & $208 \pm 8.7^{\#}$ & $1017 \pm 19.9$ \\
+ACE(1) & $9.5 \pm 0.3$ & $6.2 \pm 0.3$ & $167 \pm 3.6^{*}$ & $1016 \pm 11.5$ \\
+ACE(3) & $9.5 \pm 0.2$ & $6.5 \pm 0.2$ & $172 \pm 3.6^{*}$ & $1021 \pm 12.4$ \\
\hline
\end{tabular}

Abbreviations: ACEI(1 or 3), angiotensin converting enzyme inhibitor, imidapril, ( 1 or $3 \mathrm{mg} \mathrm{kg}^{-1}$ per day); ALP3, alkaline phosphatase isozyme $3\left(\mathrm{IU} \mathrm{I}^{-1}\right)$; Ca, calcium $\left(\mathrm{mg} \mathrm{dl}^{-1}\right)$; Osteocalcin (Gla-OC, ng ml ${ }^{-1}$ ); OVX, overiectomy; P, phosphate (mg per $100 \mathrm{ml}$ ).

$\# P<0.05$ vs. sham. ${ }^{*} P<0.05$ vs. OVX.
${ }^{\#} P<$.

this model. There is no difference in the serum calcium and phosphate level in each group, whereas the increase in the serum ALP3 level by OVX was significantly attenuated by imidapril (Table 2). The serum osteocalcin level and urinary calcium (data not shown) are not well correlated with the results in this model. These results suggest that an ACE inhibitor attenuated osteoporosis induced by estrogen deficiency and high blood pressure.

In vivo effects of $\mathrm{L}-\mathrm{NAME}$ on osteoporosis in a rat OVX model As ACE inhibitors possess the effects of both a blockade of RAS and an activation of the bradykinin-nitric oxide pathway, we examined the contribution of both pathways in an OVX-induced osteoporosis model. We have already reported that the administration of a subpressor dose of Ang II accelerated the increase in TRAP activity in the tibia, accompanied by a significant decrease in bone density and an increase in urinary deoxypyridinoline. To clarify the contribution of the bradykinin-nitric oxide pathway to osteoporosis, we used a Wistar rat OVX model of estrogen deficiency with or without a longterm administration of L-NAME $\left(1 \mathrm{mg} \mathrm{ml}^{-1}\right.$ in drinking water). ${ }^{16}$ Unexpectedly, OVX did not induce osteoporosis in the Wistar rat model, and administration of L-NAME did not alter TRAP activity (Figures $3 \mathrm{a}-\mathrm{c}$ ), urinary deoxypyridinoline (Figure $3 \mathrm{~d}$ ) or bone density (Figure 3e) in ovariectomized rats. We further examined the effect of imidapril ( $1 \mathrm{mg} \mathrm{kg}^{-1}$ per day) with or without the administration of L-NAME in ovariectomized SHR. Similarly, the administration of L-NAME did not change ALP, TRAP and BMD (Figures $4 \mathrm{a}-\mathrm{d}$ ). These results suggest that activation of RAS, but not that of the bradykinin-nitric oxide pathway, might be involved in the process of estrogen deficiency-induced osteoporosis.

\section{DISCUSSION}

Clinical epidemiological evidence has shown that high blood pressure is associated with an increase in bone loss, especially in elderly women. ${ }^{9}$ Interestingly, an analysis of a retrospective case-control study in a large population of men and women with ages ranging from 30 to 79 years (601 fracture cases and 120819 controls) has shown that thiazide diuretics, $\beta$-blockers and ACE inhibitors significantly reduced fracture risk. However, calcium channel blockers had no effect on fracture risk, and there is no evidence of a therapeutic efficacy of calcium channel blockers for the treatment of osteoporosis associated with hypertension. Interestingly, ACE inhibitors were effective in increasing BMD in women with the ACE DD polymorphism, which is associated with increased serum Ang II. ${ }^{19}$

Ang II indirectly promoted the differentiation and activation of osteoclasts responsible for bone resorption through the upregulation of the activator of the NF- $\kappa \mathrm{B}$ (nuclear factor- $\kappa \mathrm{B}$ ) ligand (RANKL, also known OPGL, TRANCE and ODF) in osteoblasts. ${ }^{15,20}$ Ang II may also influence calcium metabolism by decreasing ionized calcium and increasing the parathyroid hormone level. ${ }^{21}$ Indeed, Ang II receptor 
a

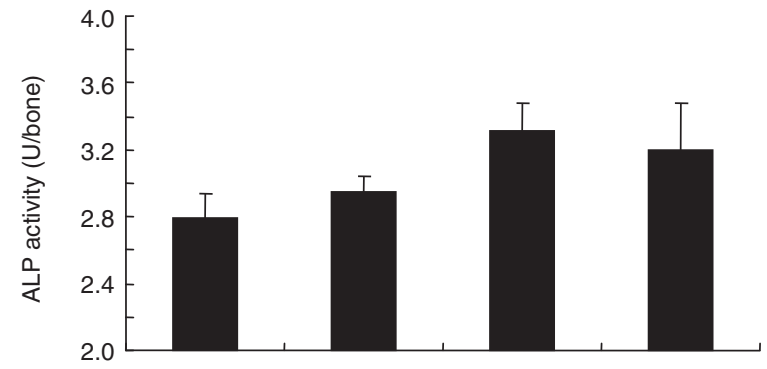

b

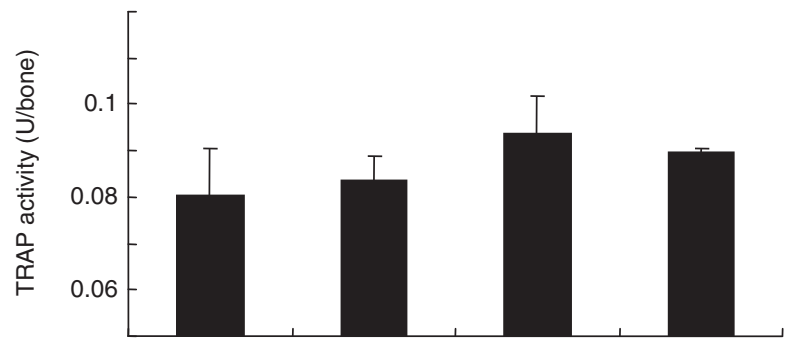

C

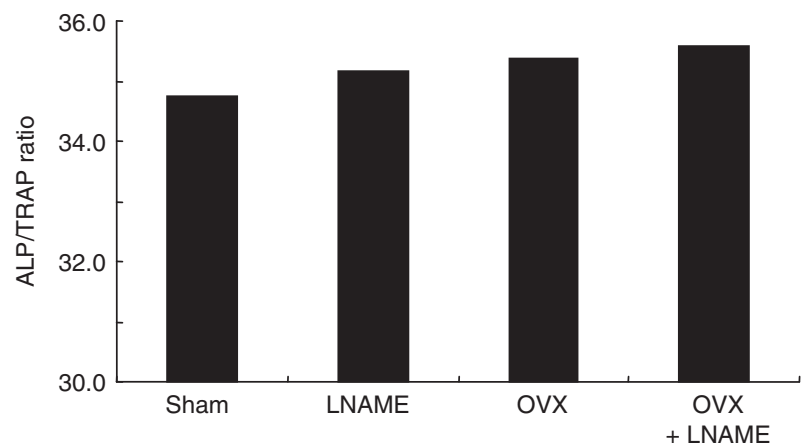

d

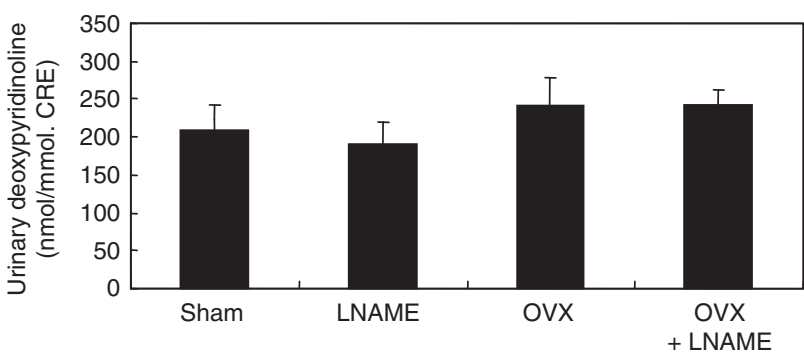

e

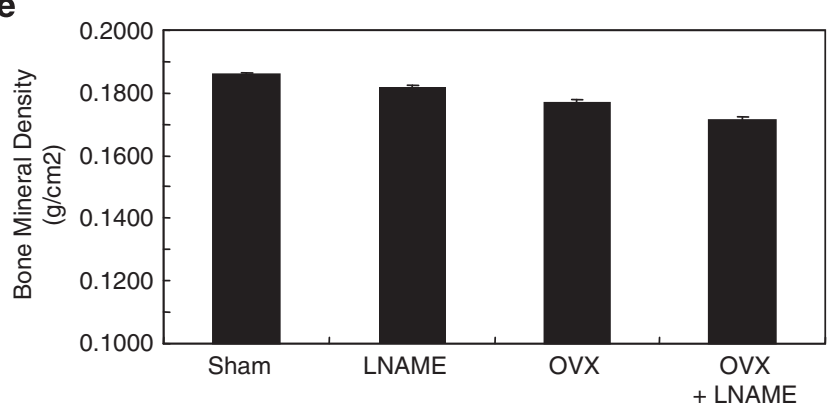

Figure 3 Effects of nitro-L-arginine methylester (L-NAME) treatment in ovariectomized Wistar rats. (a) Alkaline phosphatase (ALP) activity, (b) tartrateresistant acid phosphatase (TRAP) activity, (c) ratio of TRAP to ALP activity, (d) Urinary deoxypyridinoline and (e) bone mineral density determined by dualenergy X-ray absorptiometry (DEXA) after 28 days of each treatment. Sham, sham operation; L-NAME, administration of L-NAME $\left(1 \mathrm{mg} \mathrm{ml}^{-1}\right.$ in drinking water); OVX, bilateral ovariectomy; OVX+L-NAME, bilateral ovariectomy and administration of L-NAME ( $1 \mathrm{mg} \mathrm{ml}^{-1}$ in drinking water). $N, 6-10$ per group. a

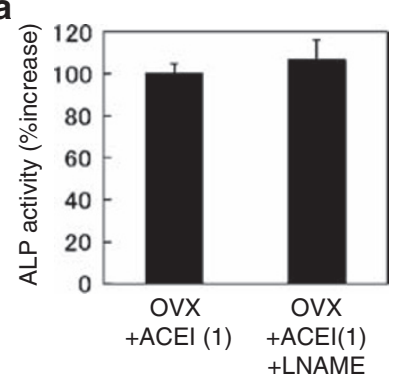

C

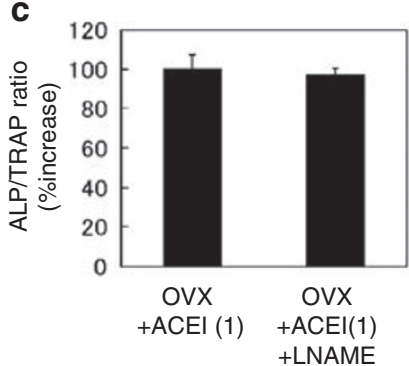

b
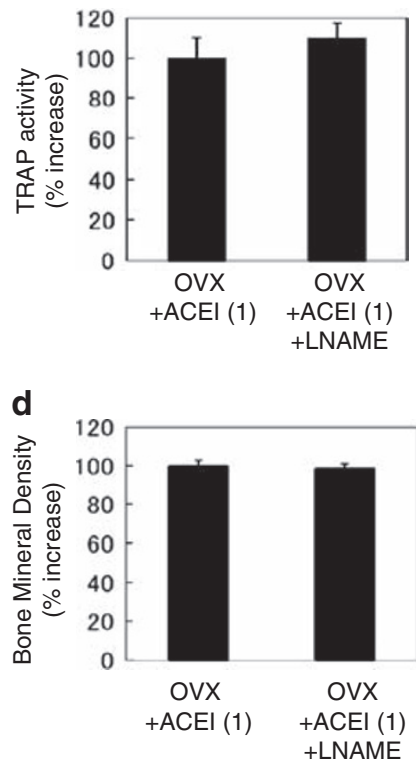

Figure 4 Effects of angiotensin-converting enzyme (ACE) inhibitor, imidapril, with or without nitro-L-arginine methylester (L-NAME) treatment in ovariectomized spontaneous hypertensive rats (SHRs). (a) Alkaline phosphatase (ALP) activity, (b) tartrate-resistant acid phosphatase (TRAP) activity, (c) ratio of tartrate-resistant acid phosphatase (TRAP) to ALP activity, (d) bone mineral density determined by dual-energy $\mathrm{X}$-ray absorptiometry (DEXA) after 28 days of each treatment. OVX+ACEI(1), bilateral ovariectomy and treatment with an ACE inhibitor, imidapril $\left(1 \mathrm{mg} \mathrm{kg}^{-1}\right.$ per day); L-NAME, administration of L-NAME $\left(1 \mathrm{mg} \mathrm{ml}^{-1}\right.$ in drinking water). Values are shown in percentage increase to $\mathrm{OVX}+\mathrm{ACE}(1)$, $N, 6$ per group.

antagonists (ARB) blocked osteoclast activation, leading to an attenuation of osteoporosis. ${ }^{15}$ In addition, ACE inhibition also prevented osteoporosis, as shown in this study. However, ACE inhibitors also regulate the bradykinin - nitric oxide $(\mathrm{NO})$ pathway as well as block Ang II production, different from ARB. It is well known that the NO pathway regulates local blood flow in bone marrow capillaries, which might enhance bone marrow formation. Thus, the contribution of the NO pathway might have a role in the prevention of osteoporosis by ACE inhibition.

Nevertheless, this study showed that a long-term administration of L-NAME did not accelerate osteoporosis, whereas the administration of a subpressor dose of Ang II accelerated the increase in TRAP activity in the tibia, accompanied by a significant decrease in bone density and an increase in urinary deoxypyridinoline. ${ }^{15}$ Thus, the major contribution of ACE inhibitors toward the prevention of osteoporosis might be a result of the blockade of RAS rather than the activation of the bradykinin-NO pathway.

Previous animal studies showed that the administration of an ACE inhibitor, enalapril, did not cause significant changes in bone density, mineral content or morphometric parameters of the femur in 14week-old ovariectomized female Wistar rats. ${ }^{22}$ The difference from our study results might be because of the use of a different model (normotension vs. SHR). Similarly, in our study, OVX did not increase TRAP activity, urinary deoxypyridinoline or bone density in 10-weekold female Wistar rats. We speculate that high blood pressure is an important risk factor for osteoporosis through the activation of RAS. Interestingly, Imaoka et al. ${ }^{7}$ previously demonstrated that the exaggerated natriuresis associated with an excessive loss of calcium in urine 
may be involved in the abnormality of calcium metabolism in lowrenin hypertensive elderly patients, but not in high-renin hypertensive patients. This suggests that the activation of RAS may be independent of the abnormality of calcium metabolism.

In vasculature, Horiuchi and colleagues ${ }^{23,24}$ showed that estrogen antagonized Ang II signaling and Ang II induced atherosclerosis, which suggest that OVX might accelerate Ang II-induced signaling. Of importance, recent reports suggest that estrogen may enhance the ACE inhibition-mediated improvement of vascular remodeling in hypertension in female SHR with OVX through the inhibition of extracellular signal-regulated kinase $1 / 2 .{ }^{25}$ It supports the impact of a cross talk between estrogen and Ang II signaling in female SHR.

Overall, an ACE inhibitor, imidapril, attenuated osteoporosis in hypertensive rats through the blockade of RAS. Owing to the increasing number of elderly people and the increase in the prevalence of osteoporosis, the need for focused preventive strategies has become a public health priority. On the basis of the findings presented in this study, together with clinical findings, ACE inhibitors as well as ARB might aid in the prevention of osteoporosis in hypertensive patients.

\section{ACKNOWLEDGEMENTS}

This work was partially supported by the National Institute of Biomedical Innovation, a Grant-in-Aid from the Ministry of Public Health and Welfare, a Grant-in-Aid from Japan Promotion of Science, and through Special Coordination Funds from the Ministry of Education, Culture, Sports, Science and Technology, the Japanese Government. We thank Ms Natsuki Yasumasa for her technical support.

1 Cappuccio FP, Meilahn E, Zmuda JM, Cauley JA. High blood pressure and bone-mineral loss in elderly white women: a prospective study. Study of Osteoporotic Fractures Research Group. Lancet 1999; 354: 971-975.

2 Tsuda K, Nishio I, Masuyama Y. Bone mineral density in women with essential hypertension. Am J Hypertens 2001; 14: 704-707.

3 Pennisi P, Signorelli SS, Riccobene S, Celotta G, Di Pino L, La Malfa T, Fiore CE. Low bone density and abnormal bone turnover in patients with atherosclerosis of peripheral vessels. Osteoporos Int 2004; 15: 389-395.

4 Uyama O, Yoshimoto Y, Yamamoto Y, Kawai A. Bone changes and carotid atherosclerosis in postmenopausal women. Stroke 1997; 28: 1730-1732.

5 McCarron DA, Pingree PA, Rubin RJ, Gaucher SM, Molitch M, Krutzik S. Enhanced parathyroid function in essential hypertension: a homeostatic response to a urinary calcium leak. Hypertension 1980; 2: 162-168.

6 Hvarfner A, Bergstrom R, Morlin C, Wide L, Ljunghall S. Relationships between calcium metabolic indices and blood pressure in patients with essential hypertension as compared with a healthy population. J Hypertens 1987; 5: 451-456.

7 Imaoka M, Morimoto S, Kitano S, Fukuo F, Ogihara T. Calcium metabolism in elderly hypertensive patients: possible participation of exaggerated sodium, calcium and phosphate excretion. Clin Exp Pharmacol Physiol 1991; 18: 631-641.
8 Young EW, McCarron DA, Morris CD. Calcium regulating hormones in essential hypertension. Importance of gender. Am J Hypertens 1990; 3: 161S-166S.

9 Resnick LM, Laragh JH, Sealey JE, Alderman MH. Divalent cations in essential hypertension. Relations between serum ionized calcium, magnesium, and plasma renin activity. N Engl J Med 1983; 309: 888-891.

10 Reid IR, Ames RW, Orr-Walker BJ, Clearwater JM, Horne AM, Evans MC, Murray MA, McNeil AR, Gamble GD. Hydrochlorothiazide reduces loss of cortical bone in normal postmenopausal women: a randomized controlled trial. Am J Med 2000; 109: 362-370.

11 Schoofs MW, van der Klift M, Hofman A, de Laet CE, Herings RM, Stijnen T, Pols HA, Stricker BH. Thiazide diuretics and the risk for hip fracture. Ann Intern Med 2003; 139: 476-482.

12 Schlienger RG, Kraenzlin ME, Jick SS, Meier CR. Use of beta-blockers and risk of fractures. JAMA 2004; 292: 1326-1332.

13 Lynn H, Kwok T, Wong SY, Woo J, Leung PC. Angiotensin converting enzyme inhibitor use is associated with higher bone mineral density in elderly Chinese. Bone 2006; 38: 584-588.

14 Rejnmark L, Vestergaard P, Mosekilde L. Treatment with beta-blockers, ACE inhibitors, and calcium-channel blockers is associated with a reduced fracture risk: a nationwide case-control study. J Hypertens 2006; 24: 581-589.

15 Shimizu H, Nakagami H, Osako MK, Hanayama R, Kunugiza Y, Kizawa T, Tomita T, Yoshikawa H, Ogihara T, Morishita R. Angiotensin II accelerates osteoporosis by activating osteoclasts. FASEB J 2008; 22: 2465-2475.

16 Takemoto M, Egashira K, Usui M, Numaguchi K, Tomita H, Tsutsui H, Shimokawa H, Sueishi K, Takeshita A. Important role of tissue angiotensin-converting enzyme activity in the pathogenesis of coronary vascular and myocardial structural changes induced by long-term blockade of nitric oxide synthesis in rats. J Clin Invest 1997; 99: 278-287.

17 Shimizu $\mathrm{H}$, Nakagami H, Tsukamoto I, Morita S, Kunugiza Y, Tomita T, Yoshikawa H, Kaneda Y, Ogihara T, Morishita R. NFkappaB decoy oligodeoxynucleotides ameliorates osteoporosis through inhibition of activation and differentiation of osteoclasts. Gene Ther 2006; 13: 933-941.

18 Venken K, Boonen S, Van Herck E, Vandenput L, Kumar N, Sitruk-Ware R, Sundaram K, Bouillon R, Vanderschueren D. Bone and muscle protective potential of the prostatesparing synthetic androgen 7alpha-methyl-19-nortestosterone: evidence from the aged orchidectomized male rat model. Bone 2005; 36: 663-670.

19 Perez-Castrillon JL, Silva J, Justo I, Sanz A, Martin-Luquero M, Igea R, Escudero P, Pueyo C, Diaz C, Hernandez G, Dueñas A. Effect of quinapril, quinapril-hydrochlorothiazide, and enalapril on the bone mass of hypertensive subjects: relationship with angiotensin converting enzyme polymorphisms. Am J Hypertens 2003; 16: 453-459.

20 Asaba Y, Ito M, Fumoto T, Watanabe K, Fukuhara R, Takeshita S, Nimura Y, Ishida J, Fukamizu A, Ikeda K. Activation of renin-angiotensin system induces osteoporosis independently of hypertension. J Bone Miner Res 2009; 24: 241-250.

21 Grant FD, Mandel SJ, Brown EM, Williams GH, Seely EW. Interrelationships between the renin-angiotensin-aldosterone and calcium homeostatic systems. J Clin Endocrinol Metab 1992; 75: 988-992.

22 Broulik PD, Tesar V, Zima T, Jirsa M. Impact of antihypertensive therapy on the skeleton: effects of enalapril and AT1 receptor antagonist losartan in female rats. Physiol Res 2001; 50: 353-358.

23 Takeda-Matsubara Y, Nakagami H, Iwai M, Cui TX, Shiuchi T, Akishita M, Nahmias C, Ito $\mathrm{M}$, Horiuchi M. Estrogen activates phosphatases and antagonizes growth-promoting effect of angiotensin II. Hypertension 2002; 39: 41-45.

24 Tsuda M, Iwai M, Li JM, Li HS, Min LJ, Ide A, Okumura M, Suzuki J, Mogi M, Suzuki H, Horiuchi M. Inhibitory effects of AT1 receptor blocker, olmesartan, and estrogen on atherosclerosis via anti-oxidative stress. Hypertension 2005; 45: 545-551.

25 Garcia MP, Gimenez J, Serna M, Salom MG, Bonacasa B, Carbonell LF, Quesada T, Hernandez I. Effect of estrogen and angiotensin-converting enzyme inhibitor on vascular remodeling in ovariectomized spontaneously hypertensive rats. Menopause 2006; 13: 397-403. 